\title{
Movements of the fault of the Lake of Cavazzo in connection with the local rainfalls
}

\author{
P. CALOI* - M. MIGANI**
}

Received on October 15, 1971

SUMMARY. -. Endeniable witnesses are given for the existence of micro. movements of the fault of the Take of Cavazzo (Tolmezzo) in connection with local rainfalls. They are recorder as vertical rotations by the clinographic stations incorporated into ENEI's power station of Somplago which lias been blast out of the rock on the Western edge of the large fault of the lake. The fault in itself, which extends probably down to the ronfluence of the Melo torrent with the Tagliamento River at about $10 \mathrm{kms}$ South of the Station, lies in the NW quadrant of the vast alluvium area of the Tagliamento extending between Venzone, Gemona and Osoppo. The rotation of the vertical toward SSE may be attributed to the weight increase of the alluvium due to rainfalls. In fact, the deviation proves to be proportional to rainfalls: the heavier are the latter, the larger is the former. This suggests the idea that below the bed of the Tagliamento River there must be a large underground flood which is alimented by leakage of rainwater. It should be considered in this respect that during the summer when rainfalls are scarce, the vertical is subjected to a slow opposite movement at somplago, as if it were under the influence of a corresponding slow lightening of the SSE area.

The micromovements of the two lerlges of the fault may exert a "release" effect on the fault area such as to prevent sizeable accumulations of elastic tensions in the surrounding medium. As a matter of fact, the Somplago area has never been in the epicentre of destructive earthquakes as far as recorded history goes back, notwithstanding the high seismic character of Carnia.

* Direttore d'Osservatorio, Istituto Nazionale di Geofisica, Roma.

** E.N.EI. Compartimento di Venezia. 
1. - It was given in account of working - in experimental stage of two horizontal pendulums of exceptional power ${ }^{(1)}$ located in a well of 136 metres hight which had been sank in the rock and contains the equipment of ENEL's power station of Somplago (Tolmezzo).

Under normal conditions the recordings of the pendulums are those pertaining to the Earth's tides. Local perturbations depending on the movements of water in the piezometric well of the Station are not missing, but they can be readily distinguished.

There are often abnormal perturbations of tectonic origin or attributable to outward reasons. The latter are the subject of this study.

2. - The recording of variations of the vertical as a consequence of passages of more or less accentuated variations of the atmospheric pressure is certainly nothing new. Such variations have been recorded many times during the last decades.

The extreme sensitivity of the clinographie station of Somplago to such phenomena and to others connected with them appears to be quite new, however.

Ever since the station of horizontal pendulums is operating at the Somplago power station, the amount of cases recorded was such as to remove any doubt: there is no passage of atmospheric perturbation of some intensity which did not bring about the more or less rapid shifting of the image of one of the two components (the S33०E) out of the recording-paper, causing sharp deviations also of the other component at $90^{\circ}$.

We are limiting ourselves to report some of the most recent examples: 20-25 February 1969 (fig. 1), 21-26 April 1969 (fig. 2), 16-20 May 1969 (fig. 3), 3-9 June 1969 (fig. 4), 7-13 July 1969 (fig. 5) and many others.

Making a first comparison between the clinographic curves and the atmospheric pressure it may lead to think of an obvious correspondence between the deviation (more or less sharp) of the N33ㅇ-S33 ${ }^{\circ} \mathrm{E}$ clinographic component and the decrease of atmospheric pressure observed in the area, but when looking closer one observes two facts which cannot be explained: the time gap between the two events (variation of the vertical and decrease of atmospheric pressure) and the apparent independence between the amplitudes of the two phenomena, since small pressure variations correspond sometimes to strong vertical deviations, and viceversa. 
Here one question had to be put: is the sudden and ample deviation of " $\mathrm{A}$ " toward $\mathrm{S} 33^{\circ} \mathrm{E}$, follower by a rapid shifting of the image out of the recorder, really bound - and exclusively so - to the passage of a minimum of pressure above Somplago? One fact is assured: generally, when the atmospheric pressure gives a strong, negative leap, the vertical is deviated with the image being shifted out of the recorder. The contrary, however, is not always true, since there are frequent and ample shiftings of the light-image toward $\mathrm{S} 33^{\circ} \mathrm{F}$ without the atmospheric pressure having suffered variations beyond normal. We wondered if this could be due to exceptional high tides of the Venetian lagoons (Grado), but we got a negative answer. It could be excluded as well that phenomena of this kind are brought about by variations in the level of the near Iake of Cavazzo, of too limited a surface that even considerable variations of its level (daily variations of some decimeters) according to the requests of the near power station are apt to cause such large effects, and it could be considered very unlikely that such a regular and frequent phenomena should have some tectonic origin, so that another weather factor had to be suspected: the rainfalls. Which was actually the case. To give one example only, let us consider the event of November 19, 1970. As will be seen from fig. 9, the variation of atmospheric pressure on that day was negligible. This notwithstanding, however, the image of component " $A$ " of the horizontal pendulum to overstep quickly and abundantly its limits. The rainfall - at Somplago solely past $90 \mathrm{mms}$ in 24 hours - on that day justifies the strong and sudden variation of the vertical which happened in the area. And by referring to the rainfall, all the observed vertical variations, besides those reported by figures 1 and 16 , are justified as well.

3. Which is the reason for such an outspoken sensitivity to phenomena which elsewhere remains almost unobserved? It should not be forgotten that the upper suspension of the pendulum extends vertically up to $130 \mathrm{~ms}$ inside the mountain. Was there a differential action between the upper and the lower connection point at the basis of the power station which may have enhanced the effect of rotation? Or did the entire mountain rotate, as a rigid means? The alternative could be settled only by an horizontal pendulum which was conditioned exclusively by its base support, which was done. Dr. Migani had two horizontal pendulums built and fixed on the ground floor of the power station, near the seismic station and the other clinographic station. 
The new pendulums, whose sensitivity was much less than that of the original couple, offered an advantage over the latter by allowing generally the entire recording of the phenomenon, with the exception of particularly accentuated variations of the vertical.

The recordings of the new couple of pendulums allowed to prove that as a matter of fact the entire mountain is uniformly subjected to the inclination, even in the case of superficial perturbations such as the one here examined.

Figures 14-16 show example recordings of the phenomenon by the new couple of horizontal pendulums.

4. - The rainfalls in the area around Somplago are, therefore, the main reason of the vertical deviation recorded by the clinographic stations installed in the power station which had been blast out of the rock in the extreme North of the Lake of Cavazzo.

How can this high sensitivity of the clinographic stations to rainfalls be explained? Spontaneously one is led to think of a particular tectonic feature of the area where the above said stations are located.

Geologists observe that the predominant tectonic feature of the area consists of a series of tectonic parallel chips which overslid towards S and SW, by overlapping surfaces falling off toward $\mathrm{N}$. There are, besides, transverse faults. One of the most important of them is the fault which can be distinguished along the West side of the Lake of Cavazzo and which was discovered and studied first by E. Feruglio $\left(^{4}\right)$ (figs. 18, 19), a fracture caused by an horizontal shifting crosswise to the folds and marked by their sudden deviation toward $S$ in correspondence to the Melo Valley. The fracturing plane is accompanied by a vertical ejection around which the rock was thinly smashed.

The fracture may be followed only for a limited length as both in the North and in the South it disappears under the lake and the alluvium. It is impossible to check whether it proceeds - as R. Selli ( ${ }^{5}$ ) believes - until the confluence of the Melo in the Tagliamento River near which, on the Western side of the Melo, another transverse fracture comes in sight (fig. 18).

This fault belongs to more recent orogenetic periods (post-helvetian). Between the Helvetian and the Quaternary occurred the most intense diastrophic period with one-sided thrusts from South which caused an heavy crush followed by upheaval of the mountain folds and by 
their upset or sliding, while a vigorous compression from East twisted them and caused transverse fractures (*).

5. - The clinographic movements recorded at Somplago on the Western elge of the Iake of Cavazzo after heavy rainfalls may be in some way connected with the fault's activity.

A more or less deep fracture in the Earth's crust causes the bonds of the edges to slacken and permits relative micromovements with a certain degree of freedom. This is what may happen in the area of the Iake of Cavazzo during rainfalls. The area West of the fault is altogether mountainous. In the East, between Gemona, Osoppo, and Venzone, further there is a vast extension of alluvium which is partly cultivated and apt to absorb amounts of water when it rains, with a considerable increase of the "ground weight" so as to attract the Western edge of the fault. It must be emphasized that the resultant of the observer bendings is always directed toward SSE, that is toward the gravity centre of the area considered. In that case it must be admitted, however, that according to Selli's hypothesis, the fault is not limited to the Western side of the Iake of Cavazzo, but extends further toward Sonth where it links up with the fracture which comes to sight between Avasinis and the confluence point of the Melo with the Tagliamento River (fig. 18).

One fundamental feature of the movement is its taking place with sudden and swift deviations, while at the end of the rainfalls the return to the original position of equilibrium is very slow (figs. 15, 16), as if an underground flood, suddenly alimented, loses gradually its flow when the rain has subsided.

Apart from the way in which the micromovements of the fault of the Lake of Cavazzo take place in connection with rainfalls, and which could be looked into closer in following studies, there remains the ontstanding fact of a large fracture which is animated by an unsuspected outward cause. If the cause is that which has been viewed in the previous section, there is no doubt that the two contact surfaces of the fault

$\left(^{*}\right)$ In this connection, it is emphasized that, prescinding from the phe. nomenon object of our study, in the recordings of the clinographic station of Somplago, a slow deviation Northward is always present. The permanence of a microrotation Northward (generally North-Westward, sometimes NorthEastward), may be of tectonic origin as a persistent push southerly into the area. 
carry out relative movements when the cause is in action. The frequency of rainfalls in this area is rather high so that the said micromovements recur quite often and more or less accentuated accorling to the intensity of the perturbing cause. It may therefore well be affirmed that at least in the outer, surface part of the fault hardly great elastic tensions will accumulated as they are continuously "released" by the above said relative micromovements. In other words, thanks to those micromovements no surface earthquakes of high intensity should take place in this area. As a matter of fact, the Iake of Cavazzo has never been in the epicentre of large earthquakes as far as recorded history can tell. $\Lambda$ s can be seen from the study of Marcelli - Feliziani $(2,3)$ (fig. 20), the area of the Lake of Cavazzo appears surrounded by the epicentres of earthquakes, among which very heavy ones, from the year 0 up to 1963 . This does not give the impression of mere coincidence.

\section{REFERENCES}

(1) CalOI P., 1969. - Relazioni fra sismicità e moti lenti nella crosta terrestre. (Relations between seismicity and slow movements in the Earth's crust). "Annali di Geofisica ", XXII, 3, pp. 209-228.

(2) Fefiziani P., Marcendu T., 1965. - Il terremoto di Tolmezzo del 26 a prile 1959. I Parto: Venti secoli di storia sismica della Regione Carnica $e$ dell'Ttalia Nord-Occidentale. "Annali di Geofisica ", XVIII, 3, pp. 165̆-207.

(3) Felizian I P., Marclel. I.., 1966. - II Parte: Studio macrosismico-geologico: determinazione analitica delle grandezze ipocentrali e natura della scossa. "Annali di Geofisica ", XIX, 2, pp. 191-214.

(4) Fenuguo E., 1925. - Le Prealpi fra l Isonzo e l Arzino. "Estr. Boll. Ass. Agr. lirinlana ».

(5) Sliti R., 1963. - Schema geologico delle Alpi Garniche e Giulie occidentali. "Giomale di Goologia ", XXX. 